\title{
SPATIAL COMPARISON BETWEEN DENSELY BUILT-UP DISTRICTS FROM THE VIEWPOINT OF VULNERABILITY TO ROAD BLOCKADES WITH RESPECT TO EVACUATION BEHAVIOR
}

\author{
Kiichiro Kumagai \\ Department of Civil and Environmental Engineering, Setsunan University \\ 17-8 Ikeda-Nakamachi, Neyagawa, Osaka 572-8508, JAPAN \\ kumagai@civ.setsunan.ac.jp
}

KEY WORDS: GIS, Urban, Model, Planning, City, Simulation, Hazards

\begin{abstract}
:
In a densely built-up area, it is conceivable that road blockades will occur widely because of building collapse caused by earthquakes. The road blockades on evacuation routes have a bad influence on earthquake evacuation behavior of residents. It is required for urban management to compare vulnerability to the road blockades between densely built-up districts. The purpose of this study is to discuss a methodology of comparison of the vulnerability based on road blockade risk between the districts. Behavior of the building collapse generally depends on a location of an earthquake's epicenter, intensity of an earthquake motion, and a type of tremor. Various kinds of simulation methods for reproduction of earthquakes have been developed, and estimation methods for damages have depended on the result of the simulation. In the comparison of the districts, an independent method however is also needed because of preventing the damages caused by an unexpected earthquake. We used building properties and Japan Engineering Geomorphologic Classification Map so that we calculated building collapse risk as a relative value. The risk was then applied to GIS analysis to determine risk of road blockade. We applied the road blockade risk as probability to the Monte Carlo simulation for making road blockade patterns. To transform the number of patterns to an index for the district comparison, we determined evacuation sites as key points, and we executed the network voronoi division along the road networks using every result of the simulation. The number of patterns based on the results of the network voronoi division was newly defined as a confusion index in a road-by-road basis: the index meant variations in a ranking of the shortest distance from the evacuation sites. We also calculated isolated roads from the evacuation sites using the results of the network voronoi division while the network spatial analysis was applied to the road blockade patterns from the view point of multidirectional evacuation. We discussed these analysis results using a land use map, historical properties of development, and other data of geographic information.
\end{abstract}

\section{INTORODUCTION}

In a densely built-up area, it is conceivable that road blockades will occur widely because of building collapse caused by earthquakes. The road blockades on evacuation routes have a bad influence on earthquake evacuation behavior of residents.

The evacuation behavior has been studied in various fields. Kady and Davis (2009) investigated the impact of route design on evacuation times for crawling movements in a building. They showed that both gender and BMI were major physical determinants of evacuation time of crawlers in an indirect route. Tang, et al. (2008) pointed out that the purpose of evacuation plan diagrams was for readers to comprehend and plan an evacuation route, and the understanding such diagrams influenced the times that they spent planning their escape route. Chin, et al. (2008) analyzed the situation in which evacuees were given a set of system-optimal paths; the evacuees chose their evacuation routes, following a certain route-choice behavior. A behavior-robust feedback information routing strategy was also proposed to update the advised routes. Based on a survey for understanding the people's decision making process for evacuation routes, a prototype version of multiagent simulation system was developed (Xu (2007), Lui, et al. (2008)).

The optimal routing of evacuees in emergency situation has been generally discussed in various fields (Francis(1981), Smith (1988), Vargas-Villamil (2006), Lu,et al.(2006)). Ferranti, et al.
(2008) devised distribution algorithms that allowed agents to dynamically discover and maintain short evacuation routes connecting emergency exits from a building. They proposed two evacuation route discovery mechanisms and integrated them with existing exploration algorithms. An approach for managing crowd evacuation from buildings was also suggested (Pizzileo, et al., 2010). Total egress time was reduced through driving individuals towards less congested exits and comparing between the predicted evacuation times from each exit. On a county or city scale, optimization of evacuation traffic on road networks has been discussed. Raub, et al. (1998) examined fifteen incidents involving crashed and disabled vehicles, and headways were measured and estimates of vehicles flow rates computed. Cova, et al. (2003) proposed a network flow model for identifying optimal lane-based evacuation routing plans in complex road network. The model included an intersection model because most traffic delays in regional evacuations occurred at intersections. An evacuation route control strategy based on real-time data for urban freeways was also propounded for speed up egress (So, et al., 2010). On the other hands, Yuan, et al. (2006) indicated the use of prespecified destinations for evacuees almost resulted in less-than-optimal evacuation efficiency because of uncertain road conditions including traffic congestion, road blockage, and other hazards associated with emergency.

For urban management, it is required to compare vulnerability to the road blockades between densely built-up districts. The purpose of this study is to discuss a methodology of comparison 
of the vulnerability based on road blockade risk between the districts. Behavior of the building collapse generally depends on a location of an earthquake's epicenter, intensity of an earthquake motion, and a type of tremor. Various kinds of simulation methods for reproduction of earthquakes have been developed, and estimation methods for damages have depended on the result of the simulation. In the comparison of the districts, an independent method however is also needed because of the prevention of damages caused by an unexpected earthquake.

\section{MATERIALS AND METHODS}

\subsection{Study Area}

In this study, the whole area of the Neyagawa city was adopted as the area of interest. This area is located in the Osaka prefecture in the western part of the Japan. It covers about $5 \mathrm{~km}$ in an east-west direction and $5 \mathrm{~km}$ in a north-south direction. The Neyagawa city has a population of about 250 thousand. There are various types of districts in this area: densely built-up districts developed rapidly during high economic growth period after World War II, district planned areas, districts developed through surveying and estimation of crop yields during the latter half of the 16th century.

\subsection{Geographical Data}

We used the Digital Map 2500 (Spatial Data Framework) and the Fundamental Geospatial Data issued by the Geospatial Information Authority of Japan. Center lines of roads, blocks, and outlines of buildings were prepared from these data sources. The Japan Engineering Geomorphologic Classification Map and the Digital Map 5m Grid (Elevation) were applied as geotechnical data (Wakamatsu, et al., 2004). House ledger was digitized for the extraction of building properties: structure, date of construction, and floor level. In cases where the analysis can be carried out in broad areas (e.g. multiple cities or one all prefecture), much effort will be expended on digitizing the house ledger. The house ledger is however basic information for the management of a real estate tax. It will be previously digitized through the spread of GIS in local governments. Evacuation sites were geocoded from a disaster prevention map of the Neyagawa city through the CSV Address Matching Service provided by the Center for Spatial Information Science in Tokyo University, and point data of the evacuation sites were acquired.

\subsection{Methods}

Figure 1 shows a flow diagram of the method proposed in this study. The method consists of 4 stages: calculation of building collapse risk, calculation of road blockade risk, making road blockade patterns, and obtaining isolated roads and a confusion index. Techniques of earthquake-resistant engineering and geographical information science permitted the execution of the method. Detail of the method will be mentioned in the paragraphs that follow.

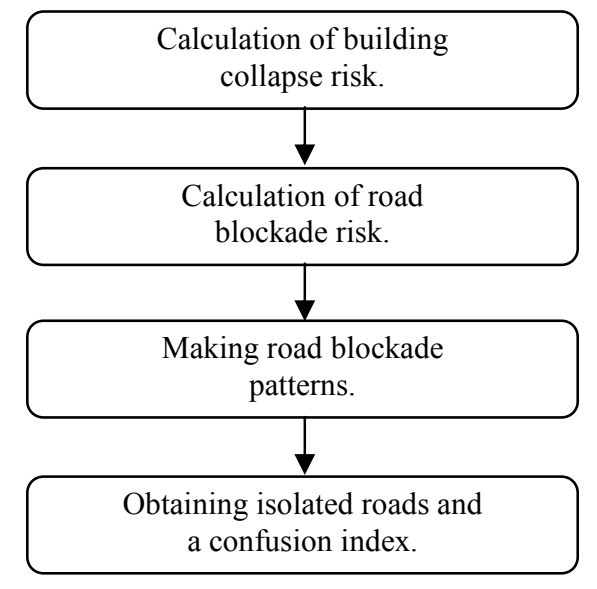

Figure 1 Flow diagram of the method proposed in this study. The method consists of 4 stages: calculation of building collapse risk, calculation of road blockade risk, making road blockade patterns, and obtaining isolated roads and a confusion index.

2.3.1 Calculation of building collapse risk: Behavior of the building collapse generally depends on a location of an earthquake's epicenter, intensity of an earthquake motion, and a type of tremor. It is also needed to compare between districts independently of the earthquake attribute. The building collapse risk applied in this study has been defined by opinions of experts on earthquake disasters (e.g. the Great Hanshin-Awaji Earthquake Disaster). Table 1 shows the building collapse risk. Building properties (the structure and the date of construction) and geomorphological land class chose the building collapse risk for assignment of a relative weight to the building (Murao, et al., 2000).

Table 1. Building collapse risk applied in this study. Building properties (the structure and the date of construction) and geomorphological land class choose the building collapse risk for assignment of a relative weight to the building (Murao, et al., 2000).

\begin{tabular}{c|c|r|r|r|r|r|r}
\hline & & \multicolumn{6}{|c}{ Geomorphological land class } \\
\cline { 3 - 8 } Structure & $\begin{array}{c}\text { Date of } \\
\text { construction }\end{array}$ & Hill & $\begin{array}{c}\text { Alluvial } \\
\text { fan low } \\
\text { grounds }\end{array}$ & $\begin{array}{c}\text { Gravelly } \\
\text { terrace }\end{array}$ & $\begin{array}{c}\text { Volcanic } \\
\text { ash terrace }\end{array}$ & $\begin{array}{c}\text { Delta low } \\
\text { grounds } \\
\text { (sand) }\end{array}$ & $\begin{array}{c}\text { Delta low } \\
\text { grounds } \\
\text { (mud) }\end{array}$ \\
\hline \multirow{4}{*}{ Wooden } & -1961 & 16.0 & 9.1 & 13.1 & 46.0 & 41.9 & 60.6 \\
building & $1962-1971$ & 8.6 & 3.9 & 6.5 & 36.9 & 32.4 & 53.6 \\
& $1972-1981$ & 7.6 & 3.3 & 5.7 & 35.6 & 31.0 & 52.7 \\
& $1982-1991$ & 2.2 & 0.8 & 1.5 & 14.6 & 12.1 & 25.6 \\
& $1992-$ & 1.0 & 0.4 & 0.7 & 5.6 & 4.7 & 10.0 \\
\hline & -1981 & 3.5 & 2.1 & 2.9 & 10.9 & 9.7 & 16.0 \\
RC building & $1982-1991$ & 0.9 & 0.4 & 0.7 & 4.2 & 3.5 & 7.1 \\
& $1992-$ & 0.5 & 0.3 & 0.4 & 1.7 & 1.5 & 2.7 \\
\hline \multirow{2}{*}{ Steel } & -1981 & 13.2 & 8.8 & 11.4 & 30.3 & 27.9 & 39.5 \\
construction & $1982-1991$ & 1.9 & 0.9 & 1.5 & 9.5 & 8.0 & 15.8 \\
& $1992-$ & 1.0 & 0.6 & 0.9 & 3.6 & 3.2 & 5.7 \\
\hline Light-weight & -1981 & 8.8 & 5.3 & 7.3 & 24.9 & 22.4 & 34.5 \\
steel & $1982-1991$ & 2.7 & 1.9 & 2.4 & 6.2 & 5.7 & 8.4 \\
construction & $1992-$ & 2.1 & 1.5 & 1.9 & 4.5 & 4.2 & 6.1 \\
\hline
\end{tabular}


2.3.2 Calculation of road blockade risk: Road blockade risk was calculated from the building collapse risk. Likewise, relationship of locations between road and buildings was required for detection of road blockade caused by building collapse. Laefer, et al. (2006) mentioned an influence of fallen trees on the safe and uninterrupted use of the road transportation system during storm events, and they proposed a methodology for automating the tree threat identification process by using airborne laser altimetry data and GIS. In this study, we calculated ranges of building rubble using buffer zones (see Figure 2). The ranges of building rubble depended on the floor level derived from building properties. All directions of building rubble were approximately generated because of uncertainty of earthquakes. Discrimination of road blockade was given by comparison of locations between a road and the rages of building rubble in a building-by-building basis.

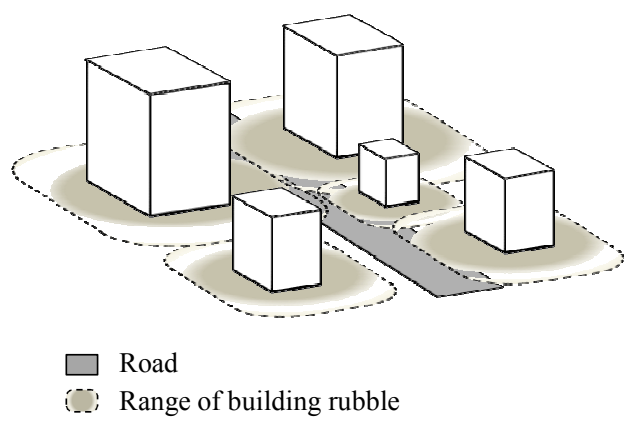

Figure 2 Comparison of locations between a road and the rages of building rubble on a building-by-building basis. Comparison led to discrimination of road blockade when the building collapse occurred.

The building collapse risk and the discrimination were then applied to GIS analysis to determine risk of road blockade. The road blockade risk on a road is derived from probability based on building collapse risk and the locational relationship between a road and rubble ranges. The probability space of road blockade on a road basically consists of the combination of building collapse events: whether building collapse occurs or not at each building around a road. The relationship between a road and rubble ranges is also added to the probability space. The road blockade risk was calculated as the probability of occurrence of both building collapse events and the road overlaid by their rubble ranges. Figure 3 shows the result of the road blockade risk.

2.3.3 Making road blockade patterns: Making road blockade patterns, we applied the road blockade risk to the Monte Carlo simulation. In the simulation, the road blockade risk was adopted as the probability of occurrence of road blockade. The simulation was executed 100 times in this study, and the road blockade patterns were obtained as the results.

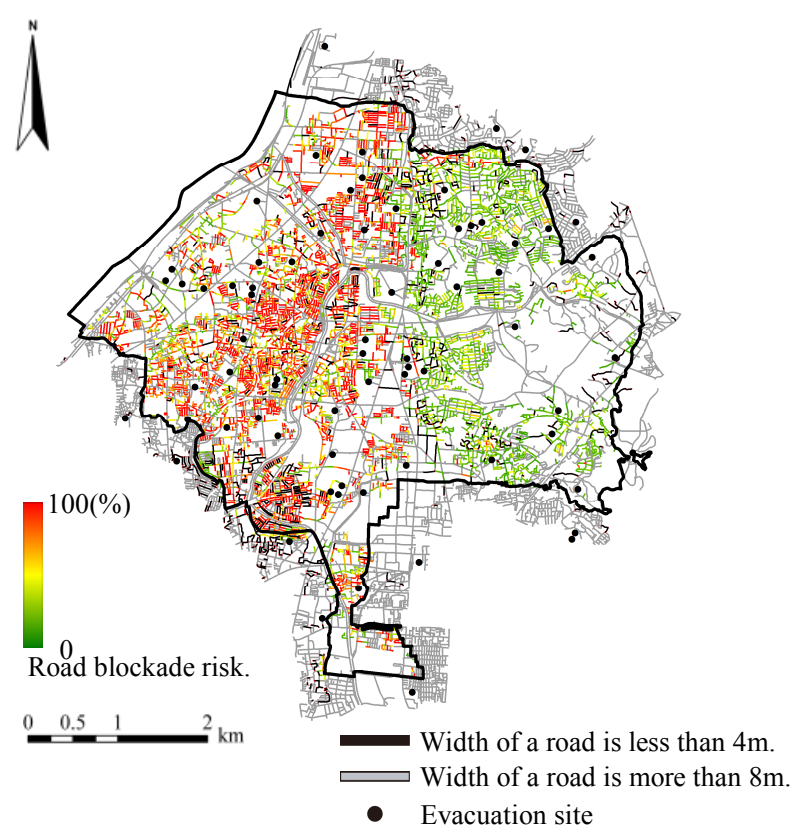

Figure 3 Result of the road blockade risk. Calculation was carried out in a road-by-road basis.

2.3.4 Obtaining isolated roads and a confusion index: To transform the number of patterns to an index for district comparison, we determined the evacuation sites as key points, and we executed the network voronoi division along road networks using every result of the simulation (Okabe, et al., 2006). The network voronoi division is a representative analysis method in the network analysis. It divides a network according to the shortest distance from the key points. Applying road network to the network voronoi division, it is clarified for evacuees which of evacuation sites is nearest located. Figure 4 reveals an example of application of network voronoi division under adoption of evacuation sites as key points in this study. The network voronoi division was then applied to the results of the simulation, and 100 results of the division were obtained.

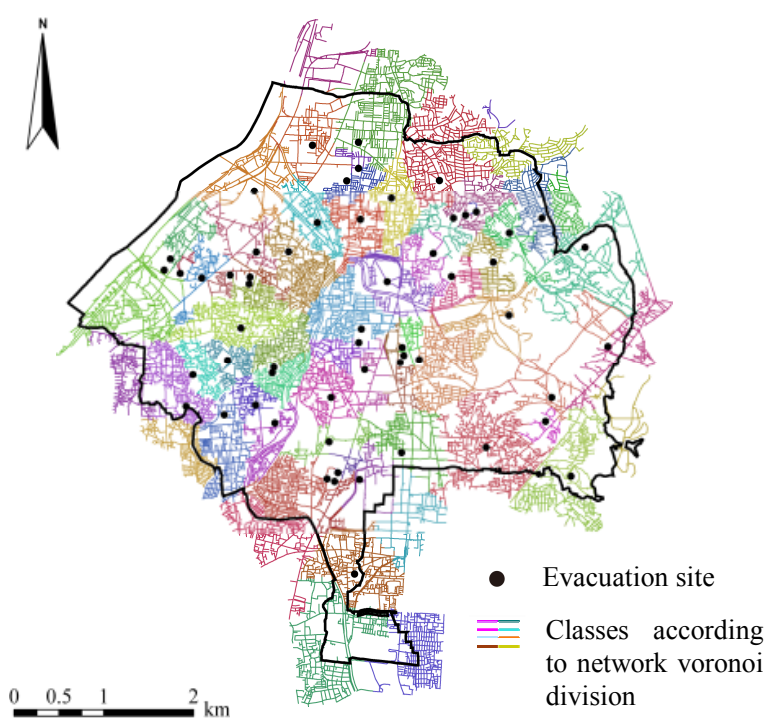

Figure 4 Example of application of network voronoi division under adoption of evacuation sites as key points. Each color of road center lines means a class according to the evacuation sites. 
Firstly, we extracted isolated roads through 100 results of network voronoi division. The no-divided roads were defined as the isolated road because it was assumed evacuation routes from the road to any evacuation site cannot be ensured by road blockade. Throughout the 100 results, the frequency of the occurrence of the no-divided road was kept count on a road-byroad basis.

Secondly, the number of patterns based on the results of the network voronoi division was newly defined as a confusion index in a road-by-road basis: the index meant variations in a ranking of the shortest distance from the evacuation sites. Figure 5 shows the procedure of making the confusion index. Through comparison between the results of network voronoi, the variation was extracted as quantity of different types of nearest evacuation sites.
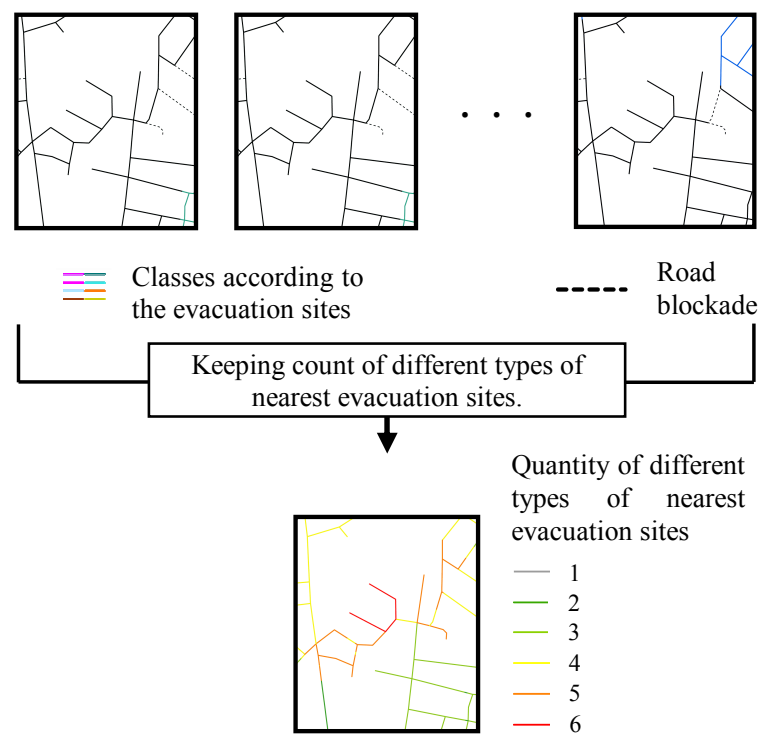

Figure 5 Procedure of making a confusion index. Variation of nearest evacuation sites caused by road blockade may provide for a confusion of the evacuation behavior. Through keeping count of different types of nearest evacuation sites using the results of network voronoi division, we could obtain the confusion index.

\section{RESULTS AND DISCUSSION}

\subsection{Results of calculation of isolated roads}

Figure 6 reveals the result of isolated roads we extracted through the network voronoi division. There are various frequencies of the occurrence of the isolated road. Low frequencies are located widely in an eastern part of the test site while high frequencies are distributed in local areas. Highest frequency (colored with blue in Figure 6) seems to be densely distributed in specific areas. Most of the areas are densely builtup districts developed rapidly during high economic growth period after World War II. Some of the densely built-up districts are designated as redevelopment zones by administration because of their vulnerability of disaster prevention.

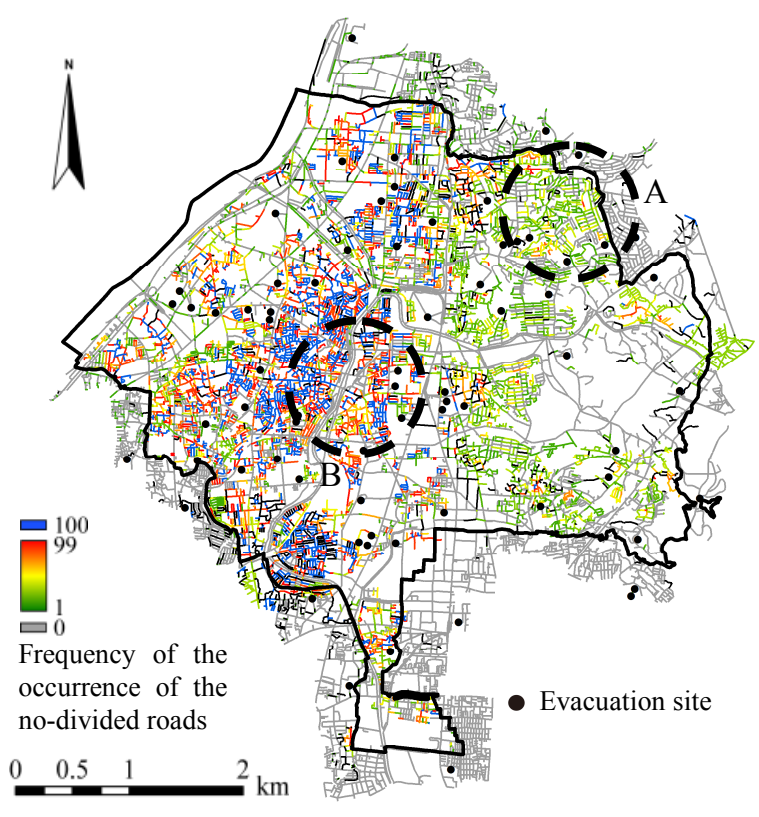

Figure 6 Isolated roads calculated in this study. Throughout the 100 results, the frequency of the occurrence of the nodivided roads was kept count on a road-by-road basis.

\subsection{Results of making a confusion index}

Figure 7 shows the result of making the confusion index. In this case, the confusion index ranged between 2 sites and 5 sites. The 1-site roads and the invariably isolated roads are widely distributed in the study area while the high road blockade risk distributed in western parts of the test site (see Figure 3). It was suggested that the evacuation sites might not be localized approximately. Already-existing public spaces (e.g. elementary/junior high/high school, university, and community center) were practically assigned to most of the evacuation sites.

On the other hands, some hotspots which include high confusion indexes appear to be located in a north-eastern part and western parts of this site. The hotspots have to be discussed through local analysis for urban planning and urban management. The hotspots were located in low-dense areas of the evacuation sites. It is required to analyze the features of the hotspots since there are also low-dense areas of the evacuation sites with low confusion indexes in the study area in Figure 7.

\subsection{Discussion}

In figures 6 and 7, the area "A" contains both the low frequencies of the occurrence of the isolated road and the hotspot of the high confusion index. The area includes actually a district planned area for preservation of residential circumstances: land use, building coverage, floor level of building, setback, and other factors of urban planning. There seems to be low dense distributions of evacuation sites around the area even though there are enough road networks. Requirement of optimizing evacuation sites is suggested through these results.

In the area " $\mathrm{B}$ ", in figures 6 and 7 , there are the high frequencies of the occurrence of the isolated road while there is also the hotspot while two evacuation sites are located in this area. In detail, the hotspot is surrounded by the high frequencies of the isolated road occurrence while the roads of the hotspot 
are assigned as no-isolated road. The hotspot seems to be derived from the more frequent isolations located around it. Redevelopment of this area may be effective for evacuation behavior.

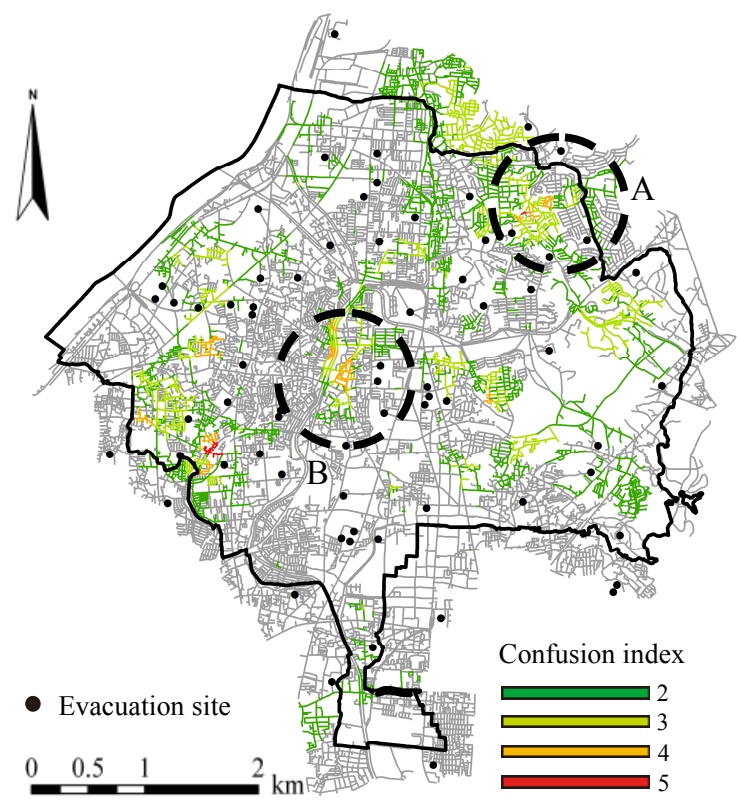

Figure 7 Confusion index proposed in this study. The confusion index ranged between 2 site and 5 sites.

\section{CONCLUSIONS}

In this study, we proposed the method of comparing the vulnerability based on road blockade risk between the districts. The method consists of the road blockade risk on the basis of the building collapse risk and the discrimination of road blockade, the Monte Carlo simulation, the network voronoi division, and the overlay analysis. The key features of the method are concluded as follows: firstly, the road blockade patterns were generated by application of the road blockade risk defined as a relative value to the Monte Carlo simulation. The number of road blockade patterns produced the complexity of evacuation routes for evacuees. Secondly, the network voronoi division was applied to every pattern through the determination of evacuation sites as key points so that the complexity became more concrete, i.e. the frequencies of the occurrence of the nodivided roads described the index with respect to the isolated road, and the number of road blockade patterns represented the confusion index for evacuation. The results of the network voronoi meant the small areas according to nearest evacuation sites along road blockade networks, and the diversity of nearest evacuation sites produced for the complexity of evacuation. Moreover, it was shown that the hotspots for the confusion index were found through application of the method. The hotspots appeared to play a key role in comparison between districts for prevention of the earthquake disasters.

As problems remaining for future research, application of population distributions to our method is required for consideration of evacuees. The population distributions depending on districts will enable us to determine weight of the complexity of evacuation.

\section{ACKNOWLEDGEMENTS}

We would like to thank the Neyagawa city for provision of the house ledger which we digitized. We also thank the Center for Spatial Information Science (CSIS) in Tokyo University for application of SANET (a toolbox for Spatial Analysis on a Network) which is free and useful software on GIS.

\section{REFERENCES}

Chiu, Y., and Mirchandani, P., 2008. Online Behavior-Robust Feedback Information Routing Strategy for Mass Evacuation, IEEE Transactions on Intelligent Transportation Systems, 9(2), pp.264-274.

Cova, T. J. andJohonson J. P. 2003. A Network Flow Model for Lane-based Evacuation Routing, Transportation Research Part A, 37(7), pp.579-604.

Ferranti, E., and Trigoni, N. 2008. Robot-Assisted Discovery of Evacuation Routes in Emergency Scenarios, Proceedings of IEEE International Conference on Robotics and Automation, 7, pp.2824-2830.

Francis, R., L. 1981. A "Uniformity Principle" for Evacuation Route Allocation, Journal of Research of National Bureau of Standards, 88(5), pp.509-513.

Laefer, D. F. and Pradhan, A. R. 2006. Evacuation Route Selection Based on Tree-Based Hazards Using Light Detection and Ranging and GIS, Journal of Transportation Engineering, 132(4), pp.312-320.

Lu, Q., George, B., and Shekhar, S. 2006. Capacity Constrained Routing Algorithms for Evacuation Route Planning, Report No.AD-A-447888, US Defense Technical Information Center.

Lui,Y., Okada, N., and Takeuchi, Y. 2008. Dynamic Route Decision Model-based Multi-agent Evacuation Simulation-Case Study of Nagata Ward, Kobe, Journal of Natural Disaster Science, 28(2), pp.91-98.

Kady, R. and Davis, J. 2009. The Impact of Exit Route Designs on Evacuation Time for Crawling Occupants, Journal of Fire Sciences, 27(5), pp.481-493.

Murao, O., Tanaka, H., Yamazaki, F., and Wakamatsu, K. 2000. New Method for Building Collapse Assessment Based on Damage Data Due to the 1995 Hyogoken-Nanbu Erathquake, Journal of Structural and Construction Engineering, 527, pp.197-204 (in Japanese).

Okabe, A. and Kitamura, M. 1996. A Computational Method for Market Area Analysis on a Network, Geographical Analysis, 28(4), pp.30-349.

Okabe, A. and Okunuki, K. 2001. A Computational Method for Estimating the Demand of Retail Stores on a Street Network and its Implementation in GIS, Transactions in GIS, 5(3), pp.209-220.

Okabe, A., Okunuki, K., and Shiode, S. 2006. SANET: A Toolbox for Spatial Analysis on a Network, Journal of Geographical Analysis, 38(1), pp.57-66. 
Pizzileo, B., Lino, P., Maione, G., and MAIONE B. 2010. A New Escape Routing Strategy for Controlling Evacuation from Buildings, Proceedings of American Control Conference, 7, pp.5124-5130.

Raub, R., A. and Pfefer, R. C. 1998. Vehicular Flow Past Incidents Involving Lane Blockage on Urban Roads. A Preliminary Exploration, Transportation Research Record, 1634, pp.86-92.

Smith, J., M. 1988. Routing in evacuation networks with QGERT and QNET-C, Proceedings of SCS Simulators Conference, pp.311-315.

So, S., K. and Daganzo, F. 2010. Managing evacuation routes, Transportation Research Part B, 44(4), pp.514-520.

Tang, C., Lin, C., and Hsu, Y. 2008. Exploratory research on reading cognition and escape-route planning using building evacuation plan diagrams, Applied Ergonomics, 39(2), pp.209217.
Vargas-Villamil, F., D. 2006. Vehicle Routing and Dispatching for Emergency Personnel Evacuation from Off-shore Oil Platforms, Proceedings of American Control Conference, 9, pp.4500-4505.

Wakamatsu, K., Matsuoka, M., Kubo, S., Hasegawa, K., and Sugiura, M. 2004. Development of GIS-Based Japan Engineering Geomorpjologic Classification Map, Journal of Japan Society of Civil Engineers, No.759/I-67, pp.213-232 (in Japanese).

Xu, W., HATAYAMA, M., and OKADA, N. 2005. Evacuationroute-based Refuge Analysis: A Case Study of Nagata Ward, Kobe City with the Help of DIMSIS, Proceedings of Infrastructure Planning, 32, pp.215-216.

Yuan, F., Han, L., D., Chin, S., and Hwang, H. 2006. Proposed Framework for Simultaneous Optimization of Evacuation Traffic Destination and Route Assignment, Transportation Research Record, 1964, pp.50-58. 